\title{
Inflammatory Bowel Diseases: focus on epidemiology
}

${ }^{1}$ Faculty of Medicine, University "Ovidius" of Constanta, Romania

\begin{abstract}
The worldwide incidence and prevalence of Inflammatory Bowel Diseases (IBD) continues to increase, recent studies showing a future global spread of Inflammatory Bowel Diseases. Epidemiological data coming for Romania are scarce.

The aim is to describe epidemiological features of Inflammatory Bowel Diseases in an adult population in the South-East side of Romania.

The retrospective and descriptive study included 128 patients: group $1=$ Crohn's Disease (CD) (79), group 2=Ulcerative Colitis (UC) (46) and group 3=Unclassified Colitis (Unclassified C) (3). We calculated the prevalence of Inflammatory Bowel Diseases in Constanţa in 2016.

The phenotypic distribution was: $62 \%$ with Crohn's Disease, $36 \%$ with Ulcerative Colitis and 3 patients with Unclassified Colitis.

Crohn's Disease: The prevalence was $0.11 / 100000$ inhabitants. $51 \%$ were female and $49 \%$ were male. The age distribution showed a uniform model of the frequency of Crohn's Disease in patients aged between 21 and 50 years. According to Montreal Classification, ileo-colonic involvement L3 was the most frequent in $47 \%$ and $60 \%$ patients presented inflammatory phenotype B1. $44 \%$ had intestinal complications. $9 \%$ had extraintestinal complications. $16.4 \%$ required surgical interventions.

Ulcerative Colitis: The prevalence was $0.06 / 100000$
\end{abstract}

\section{Cristina Tocia}

blvd Tomis nr. 211, bloc ts6b, scara c, etaj 4, ap. 38

email : cristina.tocia@yahoo.com

phone: +40740508441 inhabitants. We noticed a slight male predominance: $57 \%$ were male and $43 \%$ female. The age distribution showed a bimodal peak of incidence in patients aged between 21-30 years and 41-50 years. The most common disease extension was left colitis E2 in $47 \%$ cases. One patient had an enterovesical fistula. Extraintestinal complications were not reported in this group. No patient required surgical intervention.

Unclassified Colitis: 3 male patients with ages between 31-50 years were diagnosed with Unclassified Colitis. Complications or need for surgery were not reported in this group.

We noticed the predominance of Crohn's Disease in our region while in other parts of Romania Ulcerative Colitis is predominant. We suppose that the predominance of Crohn's Disease in Dobrogea can be due to environmental factors, diet or ethnics, but additional epidemiological studies to define better the association with environmental factors and risk factors for Crohn Disease or Ulcerative Colitis in our region are needed.

Keywords: Crohn's Disease, Ulcerative Colitis, Inflammatory Bowel Diseases, Epidemiology

\section{Introduction}

The worldwide incidence and prevalence of Inflammatory Bowel Diseases (IBD) continues to increase, recent studies showing a future global spread of IBD.

Although for years, the highest incidence and prevalence rates were noticed in westernized nations and the majority of studies were conducted in these 
geographic regions, few epidemiological data have been available about frequency of IBD in developing nations. Molodecky et al. [1] reported in his study that the highest incidence of IBD worldwide was in Canada followed by Northern Europe whereas Asia had a lower incidence, at that time suggesting a North-South gradient for IBD [2]. Since 2000, a stabilization of the values of incidence and prevalence has been noted in Western Countries; despite this, a rapidly increasing incidence has been observed in the newly industrialized countries. The concern about IBD has increased in Eastern Europe, Hungary publishing worrying data [3], so is New Zealand [4], Asia, Africa and South America [1] and much of the developing world. If IBD will continue to rise in these areas with formerly low incidence rates like in the Western Countries 30-40 years ago, then the ,global prevalence of IBD will climb steadily, affecting tens of millions of people through the world over the next generation" [5].

Epidemiological data coming for Romania are scarce. Although Romania is known as a lowincidence country of IBD [6], few studies have been conducted so far. According to the latest publications that show a global burden of IBD and increasing incidence in Eastern Europe and considering the lack of studies in Romania, we identified the need for assessing the epidemiology of IBD in the South-East side of Romania.

Aim: To describe epidemiological features of IBD in an adult population in the South-East side of Romania.

\section{Materials and methods}

The retrospective and descriptive study included 128 patients with IBD admitted to Department of Gastroenterology of Constanţa County Emergency Clinical Hospital „Sf. Apostol Andrei” and in outpatient clinic between 2014-2016.

Information was collected from the digital database of the hospital for inpatients and outpatients.
Characteristics of patients were introduced in a standard worksheet that included the following requirements: name, age, sex, type of IBD: $C D, U C$, Unclassified C, Montreal Classification for CD and extent of lesions for UC and Unclassified C, types of intestinal and extraintestinal complications and surgical interventions.

Inclusion criteria: IBD (old and new cases) and age $>16$ years.

Exclusion criteria: Irritable Bowel Syndrome (IBS) and other types of colitis (infectious colitis, microscopic colitis, ischemic colitis, radiation colitis).

The study included 3 groups of patients: group $1=\mathrm{CD}(79$ patients $)$, group $2=\mathrm{UC}(46$ patients $)$ and group 3 = Unclassified $\mathrm{C}$ ( 3 patients). We calculated the prevalence of IBD in Constanţa County in 2016 (the population was about 684,100 inhabitants at the last census done).

Data analysis with Microsoft Excel Analysis Tool Pack was performed and descriptive statistics (mean value and standard deviation) were calculated.

\section{Results}

The phenotypic distribution was: 79 patients $(62 \%)$ with CD, $46(36 \%)$ with UC and 3 patients with Unclassified Colitis.

The prevalence of IBD in our region was $0.17 / 100000$ inhabitants.

\section{CROHN'S DISEASE}

The prevalence of $\mathrm{CD}$ was $11.6 / 100000$ inhabitants.

Gender distribution

$41(51 \%)$ were female and $38(49 \%)$ were male (Figure 1). 


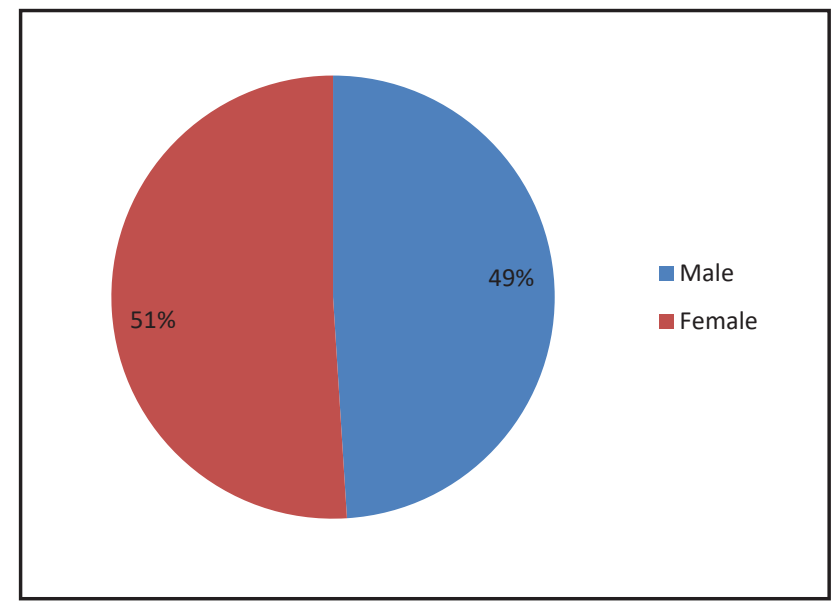

Figure 1. Gender distribution

Age distribution

The mean age was $44.5+/-15.5$ years. The age distribution showed a uniform model of the frequency of $\mathrm{CD}$ in patients aged between 21 and 50 years (Figure 2).

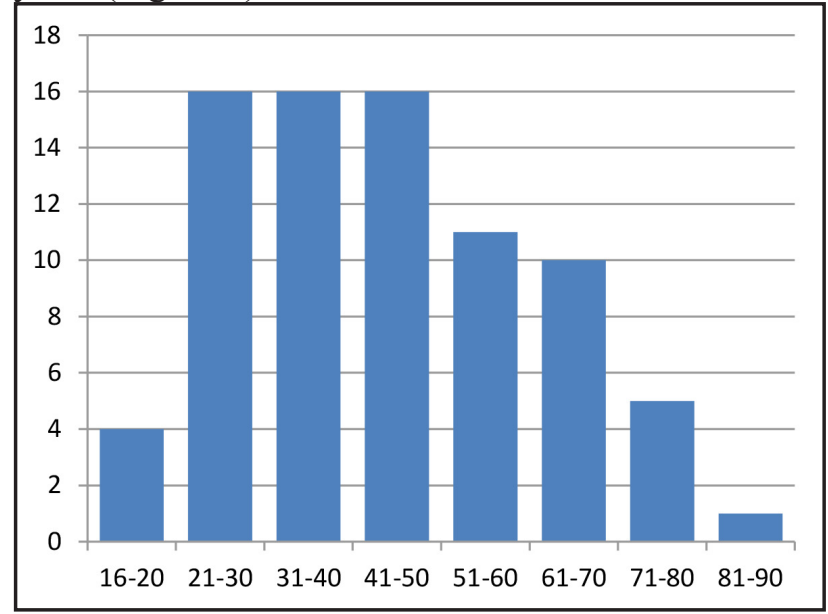

Figure 2. Age distribution

Disease Location

According to Montreal Classification, ileocolonic involvement L3 was the most frequent in 37 cases (47\%), followed by ileal L1 in 23 cases $(29 \%)$ and colonic L2 in 19 cases (24\%) (Figure 3).

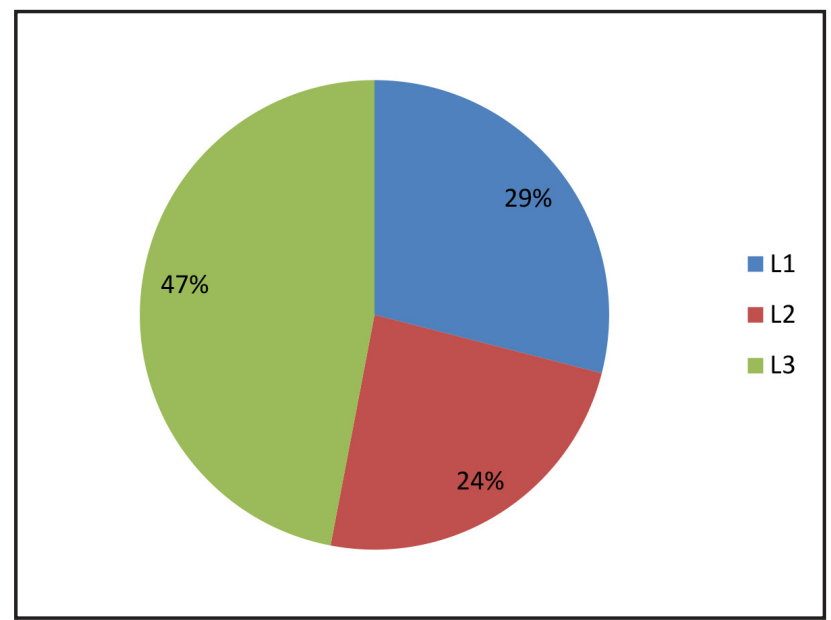

Figure 3. Disease Location

Disease Behavior

According to Montreal Classification, 48 $(60 \%)$ patients presented inflammatory phenotype B1, followed by 20 patients (26\%) with stenotic phenotype B2 and $11(14 \%)$ with penetrant phenotype B3. Only 4 patients $(5 \%)$ had perianal lesions (Figure $4)$.

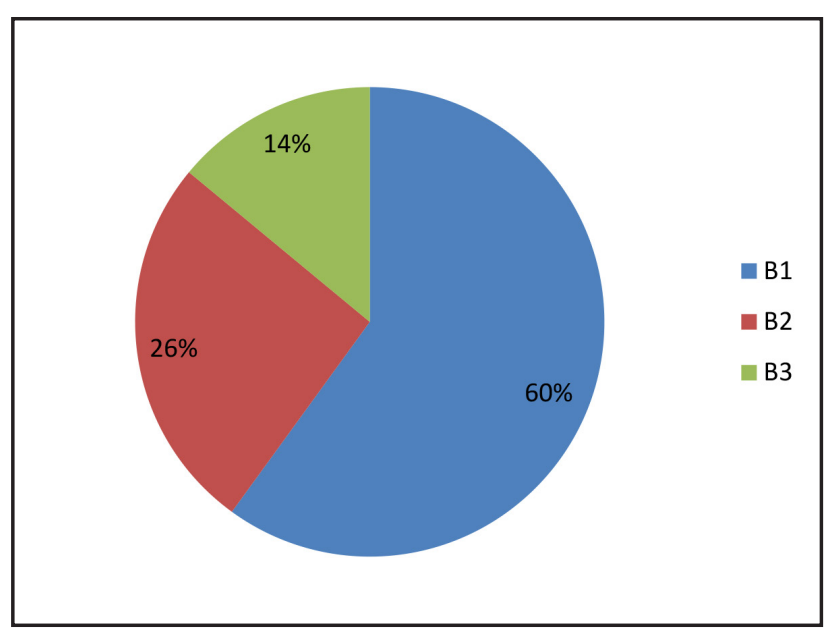

Figure 4. Disease phenotype in $C D$

\section{Complications}

35 patients (44\%) had intestinal complications at one point in the evolution of the disease (Figure 5): $20(25 \%)$ stenosis, $10(12.6 \%)$ fistulas and $5(6.4 \%)$ intraabdominal abscesses (Figure 6, Figure 7). Only 7 patients $(9 \%)$ had extraintestinal complications: 3 cases sacroileitis, 1 epislceritis, 2 CSP, 1 Renal 
Lithiasis and 2 ITU.

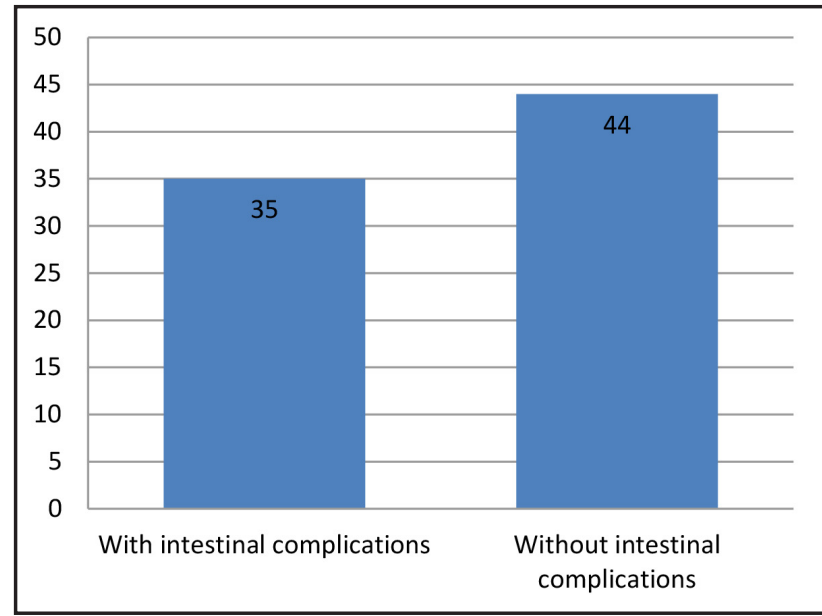

Figure 5. Distribution of intestinal complications

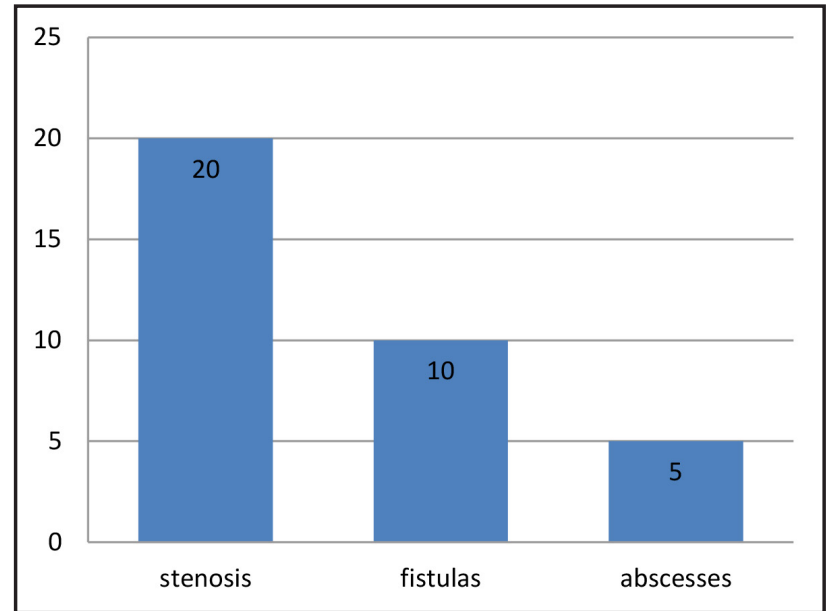

Figure 6. Types of intestinal complications

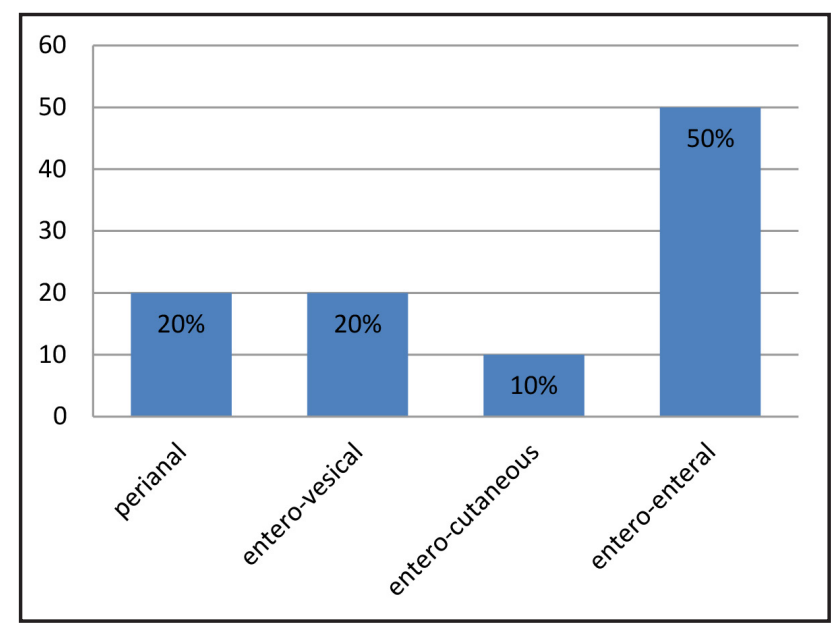

Figure 7. Types of fistulas
Surgery

13 patients (16.4\%) required surgical interventions.

ULCERATIVE COLITIS

The prevalence of UC was $6.7 / 100000$ inhabitants.

Gender distribution

This group was characterized by slight male predominance: $26(57 \%)$ were male and $20(43 \%)$ female (Figure 8)

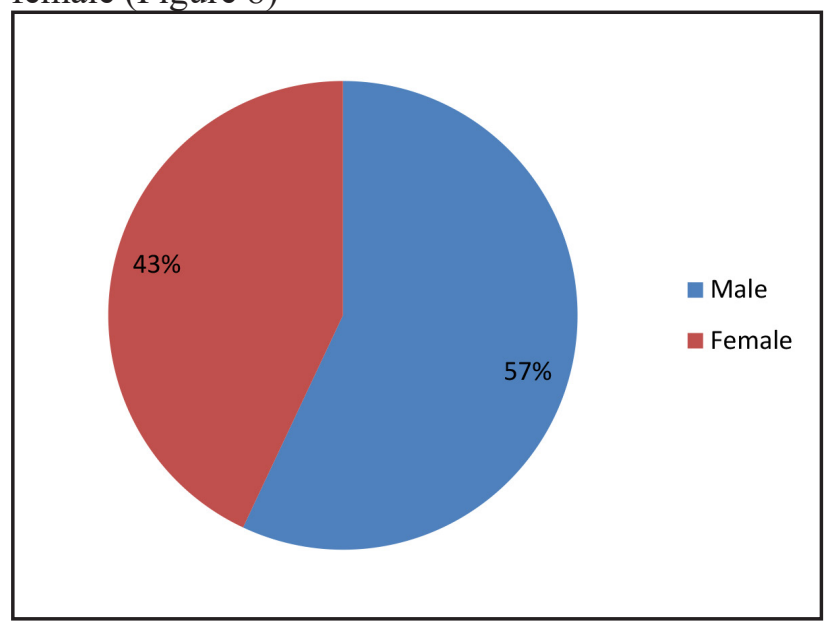

Figure 8. Gender distribution

\section{Age distribution}

The mean age was $44+/-14.2$ years. The age distribution showed a bimodal peak of incidence in patients aged between 21-30 years and 41-50 years (Figure 9).

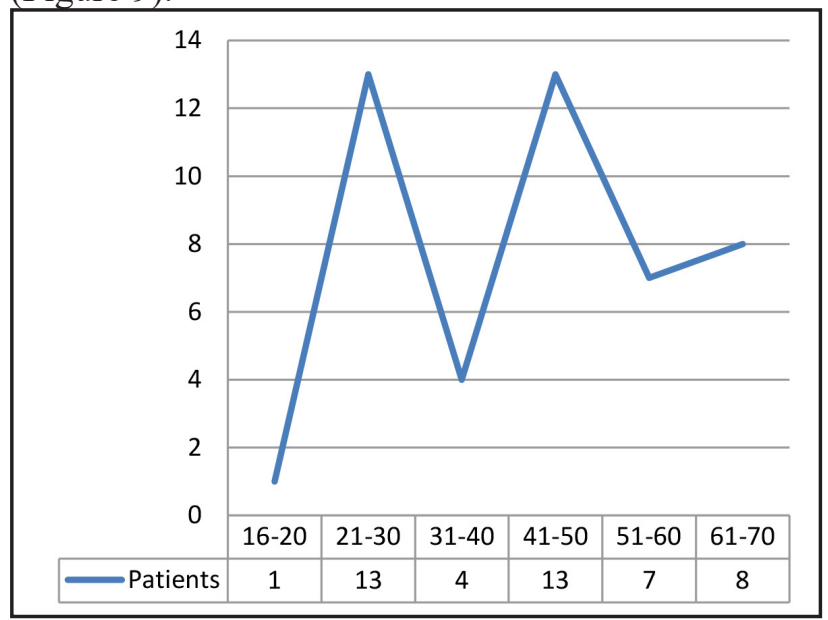

Figure 9. Age distribution 
Disease extension

The most common disease extension was left colitis E2 in 21.6 patients (47\%), followed by proctitis E1 in 18.4 patients $(40 \%)$ and extensive colitis E3 in 6 patients (13\%) (Figure 10).

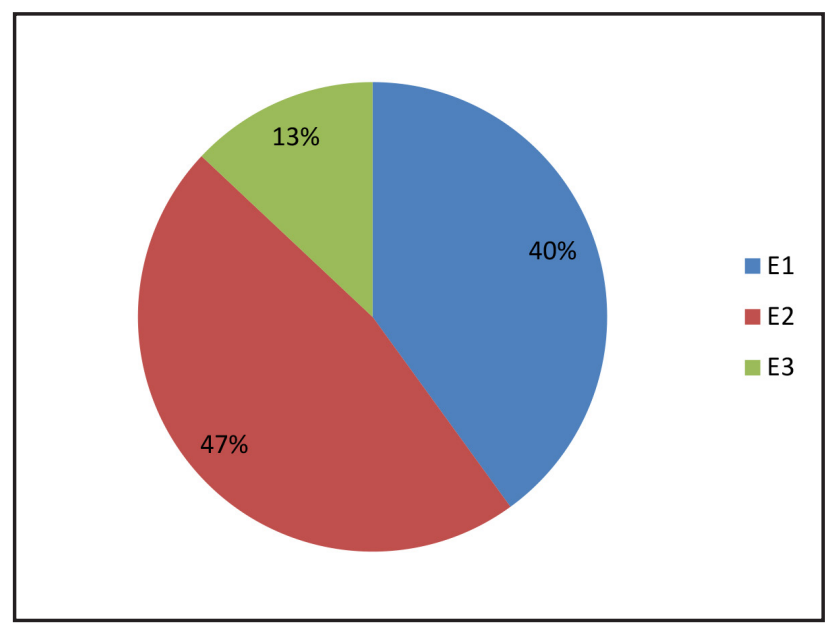

Figure 10. Disease extension in UC

Complications

Only one patient had an enterovesical fistula at one point in the evolution of the disease. Extraintestinal complications were not reported in this group.

\section{Surgery}

No patient required surgical intervention.

\section{UNCLASSIFIED COLITIS}

Only 3 male patients with ages between 3150 years were diagnosed with Unclassified Colitis (2 with left colitis E2 and one with proctitis E1). Complications or need for surgery were not reported in this group.

\section{Discussions}

An important feature of our study is the predominance of CD in Dobrogea (62\%). A similar local study conducted years ago showed the same results [7]. In contrast, other studies [8, 9, 10] published the predominance of UC in different regions of Romania and a south-west to north-east phenotypic gradient. Recent information from our National Database IBD Prospect [10] indicates that UC is predominant in our country.

The geographical distribution of IBD in Romania varies considerably (Figure 11). We suppose that the predominance of CD in Dobrogea can be due to environmental factors, diet or ethnics, but additional epidemiological studies to better define the association with environmental factors and risk factors for $\mathrm{CD}$ or UC in our region are needed.

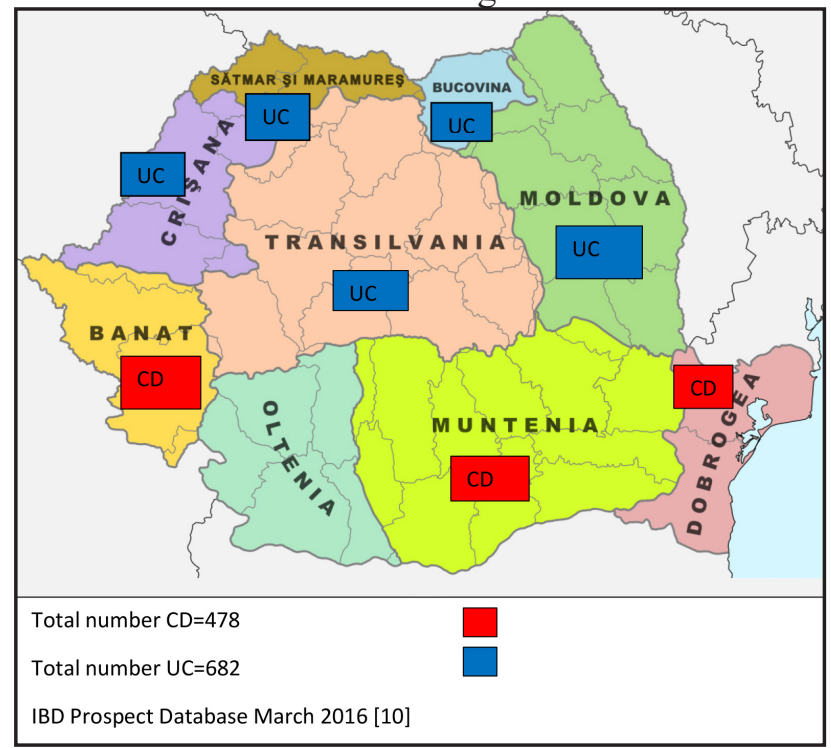

Figure 11. Geographical distribution of IBD in Romania between 2014-2016 [8, 10]

\section{CROHN'S DISEASE}

Gender and age distribution

The mean age was 44 years in both $\mathrm{CD}$ and $\mathrm{UC}$ and is higher than data available from other national studies [10] or from Europe and USA where the incidence peak is under 35 years of age [11]. In accordance with the latest study made in Dobrogea [7], more than half of the CD patients $(60.6 \%)$ had a uniformly age distribution between $21-50$ years and there were no statistical differences between male and female. These findings are in contrast with literature that indicates a high prevalence of $\mathrm{CD}$ in young females [8, 10].

Disease location

Almost half of patients had ileo-colonic L3 
involvement, similar with other studies like ESCAPE in Serbia [12] or Hungary [13], but in contradictory with the results from IBSEN Study [14] or national studies where colonic involvement L2 [7,8,9] or ileal involvement L1 [10] were predominant. We don't have information about the upper digestive tract involvement because we don't routinely perform upper GI endoscopy in our patients unless they have symptoms.

Disease behavior

In concordance with previous studies [7,8], inflammatory phenotype B1 was predominant, followed by stenotic B2 and penetrant B3 and perianal disease was present in a small percentage.

Complications

Almost half of the patients (44\%) had intestinal complications, feature also observed years ago in Romania [9], but comparing with the last study conducted in Dobrogea [7], we noticed the increase of these complications, suggesting that patients had more severe disease progression in our region.

In contrast with the ESCAPE study [12] only $9 \%$ had extraintestinal complications.

Surgery

The proportion of surgically treated patients was smaller than previously published $[9,12]$ and comparing with the latest local study [7], even if the number of intestinal complications increased over years (almost half had intestinal complications), only $16.4 \%$ needed surgery. These results suggest that remaining patients achieved response with medical treatment and surgery was avoided.

\section{ULCERATIVE COLITIS}

Gender and age distribution

In agreement with literature [9], the male to female ratio was almost similar with a slight male predominance suggesting an equal risk of developing UC. In contrast, local studies [7, 10] showed male predominance. The age distribution showed a bimodal peak of incidence in patients aged between 21-30 years and 41-50 years and it is in contrast with another study conducted in Romania [9] where the population with ages between 20-59 years were uniformly affected (this model was observed in our study in the group with $\mathrm{CD}$ ). Comparing with previous information published in our country [12] or region [7], we conclude that $\mathrm{UC}$ is beginning to affect younger patients.

Disease extension

Similar to other studies from Romania $[9,10]$, Dobrogea [7] or Hungary [13], the majority of cases were left colitis E2 (47\%), followed by proctitis E1 and extensive colitis E3.

Complications

There were no intestinal and extraintestinal complications reported in this group except one patient who had a entero-vesical fistula. On the basis of the results of previous studies [9] that showed significantly higher complications, we can say that UC in Dobrogea had a benign course.

Surgery

No patient required surgical interventions. The same results were found in another study in Romania [9] and this fact highlights the benign course of UC in our region.

UNCLASSIFIED COLITIS

In agreement with other studies [8,10], Unclassified Colitis was present in a small percentage and without particularities in our region.

\section{Conclusions}

The present study showed epidemiological features and phenotypes of IBD in Dobrogea.

We noticed the predominance of $\mathrm{CD}$ in our region while in other parts of Romania UC is predominant. We suppose that the predominance of $\mathrm{CD}$ in Dobrogea can be due to environmental factors, diet or ethnics, but additional epidemiological studies to define better the association with environmental factors and risk factors for $\mathrm{CD}$ or $\mathrm{UC}$ in our region are needed.

Gender distribution (no significant difference between male and female in $\mathrm{CD}$ and the slight male predominance in UC) confirmed that there is no relationship between gender and predisposition of developing IBD.

CD main characteristics in Dobrogea: predominance of ileo-colonic involvement L3 and 
inflammatory phenotype B1, and perianal disease were reported in a few cases. Almost half of the patients had intestinal complications (mainly stenosis and fistulas), suggesting a severe disease progression in our region, but only $16.4 \%$ needed surgery, and this indicated that remaining patients achieved response with medical treatment and surgery was avoided.

UC main characteristics in Dobrogea: the majority of cases were left colitis E2, a small percentage of extensive colitis E3, absence of intestinal and extraintestinal complications and no need for surgery in this group. All these findings highlight the benign course of UC in our region.

\section{References}

1. Molodecky, N.A., Soon, S., Rabi, D.M., Ghali, W.A., Ferris, M., Chernoff, G., Benchimol, E.I., Panaccione, R., Ghosh, S. \& Barkema, H.W. (2012). Increasing incidence and prevalence of the inflammatory bowel diseases with time, based on systematic review. Gastroenterology. 142(1), 46-54. e42.

2. Loftus, E.V. (2004). Clinical epidemiology of inflammatory bowel disease: incidence, prevalence, and environmental influences. Gastroenterology. 126(6), 1504-1517.

3. Lakatos, L., Mester, G., Erdelyi, Z., Balogh, M., Szipocs, I., Kamaras, G. \& Lakatos, P.L. (2004). Striking elevation in incidence and prevalence of inflammatory bowel disease in a province of western Hungary between 1977-2001. World journal of gastroenterology. 10(3), 404.

4. Gearry, R.B., Richardson, A., Frampton, C., Collett, J.A., Burt, M.J., Chapman, B.A. \& Barclay, M.L. (2006). High incidence of Crohn's disease in Canterbury, New Zealand: results of an epidemiologic study. Inflammatory bowel diseases. 12(10), 936-943.

5. Kaplan, G.G. \& Ng, S.C. (2017). Understanding and preventing the global increase of inflammatory bowel disease. Gastroenterology. 152(2), 313-321. e312.

6. Lovasz, B.D., Golovics, P.A., Vegh, Z. \& Lakatos, P.L. (2013). New trends in inflammatory bowel disease epidemiology and disease course in Eastern Europe. Digestive and Liver Disease. 45(4), 269-276.

7. Achim, A., Alexandrescu, L. \& Dumitru, E. (2012, September). Epidemiologia si evolutia clinica a bolilor inflamatorii intestinale in judetul Constanta. Al IV-lea Simpozion National de Boli Inflamatorii Cronice Intestinale, Sibiu.

8. Gheorghe, C., Dimitriu, A., Iacob, R., Cojocaru, M., Lupei, C., Vadan, R., Dobru, D., Trifan, A., Tantau, M. \& Goldis, A. (2014). P630 Epidemiological and phenotypic characteristics of IBD patients in Romania-results of a nationwide hospital-based registry. Journal of Crohn's and Colitis. 8(Supplement 1), S333-S333.

9. Gheorghe, C., Pascu, O., Gheorghe, L., Iacob, R., Dumitru, E., Tantau, M., Vadan, R., Goldis, A., Balan, G. \& Iacob, S. (2004). Epidemiology of inflammatory bowel disease in adults who refer to gastroenterology care in Romania: a multicentre study. European journal of gastroenterology \& hepatology. 16(11), 1153-1159.

10. Zaharie, R., Tantau, A., Zaharie, F., Tantau, M., Gheorghe, L., Gheorghe, C., Gologan, S., Cijevschi, C., Trifan, A. \& Dobru, D. (2015). Diagnostic delay in Romanian patients with inflammatory bowel disease: risk factors and impact on the disease course and need for surgery. Journal of Crohn's and Colitis. 10(3), 306-314.

11. Burisch, J., Pedersen, N., Čuković-Čavka, S., Brinar, M., Kaimakliotis, I., Duricova, D., Shonová, O., Vind, I., Avnstrøm, S., Thorsgaard, N., Andersen, V., Krabbe, S., Dahlerup, J.F., Salupere, R., Nielsen, K.R., Olsen, J., Manninen, P., Collin, P., Tsianos, E.V., Katsanos, K.H., Ladefoged, K., Lakatos, L., Björnsson, E., Ragnarsson, G., Bailey, Y., Odes, S., Schwartz, D., Martinato, M., Lupinacci, G., Milla, M., De Padova, A., D'Incà, R., Beltrami, M., Kupcinskas, L., Kiudelis, G., Turcan, S., Tighineanu, O., Mihu, I., Magro, F., Barros, L.F., Goldis, A., Lazar, D., Belousova, E., Nikulina, I., Hernandez, V., Martinez-Ares, D., Almer, S., 
Zhulina, Y., Halfvarson, J., Arebi, N., Sebastian, S., Lakatos, P.L., Langholz, E. \& Munkholm, P. (2014). East-West gradient in the incidence of inflammatory bowel disease in Europe: the ECCO-EpiCom inception cohort. Gut. 63(4), 588-597. doi: 10.1136/gutjnl-2013-304636.

12. Krstic, M., Tarabar, D., Bojic, D., Nagorni, A., Hadnadjev, L., Dugalic, P., Nikolic, G., Brocic, T., Milenkovic, Z. \& Gligorijevic, V. (2012). P421 Epidemiological study of occurrence, clinical course and treatment options of IBD in Serbia. Results of ESCApe study. Journal of Crohn's and Colitis. 6, S177.
13. Lakatos, L., Kiss, L.S., David, G., Pandur, T., Erdelyi, Z., Mester, G., Balogh, M., Szipocs, I., Molnar, C. \& Komaromi, E. (2011). Incidence, disease phenotype at diagnosis, and early disease course in inflammatory bowel diseases in Western Hungary, 2002-2006. Inflammatory bowel diseases. 17(12), 2558-2565.

14. Solberg, I.C., Vatn, M.H., Høie, O., Stray, N., Sauar, J., Jahnsen, J., Moum, B., Lygren, I. \& Group, I.S. (2007). Clinical course in Crohn's disease: results of a Norwegian populationbased ten-year follow-up study. Clinical Gastroenterology and Hepatology. 5(12), 14301438. 